RESEARCH PAPER

\title{
Smoking cessation treatment in primary care: prospective cohort study
}

\author{
A Wilson, J Hippisley-Cox, C Coupland, T Coleman, J Britton, S Barrett
}

Tobacco Control 2005;14:242-246. doi: 10.1136/tc.2004.010090

See end of article for authors' affiliations

.....................

Correspondence to: Dr Andrew Wilson Department of Health Sciences, Division of General Practice \& PHC, University of Leicester, Leicester General Hospital, Gwendolen Road, Leicester LE5 4PW, UK; aw7@le.ac.uk

Received

22 September 2004

Accepted

10 February 2005 of smokers who do and do not receive smoking cessation Objective: To compare the characteristics of smokers who do and do not receive smoking cessat
treatment in primary care.
Design: Prospective cohort study using practices registered with the pilot QRESEARCH database. Setting: 156550 patients aged 18 years and over from 39 general practices located within four strategic health authorities, representing the former Trent Region, UK.

Subjects: Patients registered with practices between 1 April 2001 and 31 March 2003 aged 18 years and over who were identified as smokers before the two year study period.

Outcome: Prescription for smoking cessation treatment (nicotine replacement therapy (NRT) or bupropion) in the two year study period.

Variables: Age, sex, deprivation score, co-morbidity.

Results: Of the 29492 patients recorded as current smokers at the start of the study period 1892 (6.4\%) were given prescriptions for smoking cessation treatment during the subsequent two years. Of these, 1378 (72.8\%) were given NRT alone, 406 (21.5\%) bupropion alone, and 108 (5.7\%) both treatments. Smokers were more likely to receive smoking cessation treatment if they lived in the most deprived areas (odds ratio (OR) for the most relative to the least deprived fifth, adjusted for sex, age, and co-morbidity, 1.50, 95\% confidence interval (CI) 1.26 to 1.78), and if they were aged 25-74 years compared to 18-24 years or 75 and over. Smokers with co-morbidity were also more likely to receive smoking cessation treatment. Smokers were less likely to receive smoking cessation treatment if they were male (adjusted OR 0.68, 95\% $\mathrm{Cl} 0.62$ to 0.75$)$.

Conclusion: The low proportion of smokers being prescribed these products strongly suggests that a major public health opportunity to prevent smoking related illness is being missed.
$\mathrm{T}$ he health benefits of giving up cigarette smoking, even in late middle age, has recently been quantified by Doll et al. ${ }^{1}$ Their results suggest that stopping at age 30 reduces the loss of 10 years life expectancy suffered by those who continue to smoke to nearly zero, and that stopping at 50 reduces loss of life expectancy to four years. This is a clear and encouraging message for general practitioners to give to patients wishing to stop smoking, especially given the availability of effective drugs to support cessation and the national provision of specialist cessation services. In the UK bupropion has been available on National Health Service (NHS) prescription since June $2000^{2}$ and nicotine replacement therapy (NRT) from April 2001. ${ }^{3}$ Primary care trusts (PCTs) have commissioned smoking cessation services since April 2002, ${ }^{4}$ and been set ambitious targets for abstinence rates. $^{5}$

Primary care has a major role in delivering smoking cessation interventions. ${ }^{56}$ Guidelines published by Thorax ${ }^{7}$ and the National Institute for Clinical Excellence (NICE) ${ }^{8}$ recommend strongly that smoking status is ascertained and brief cessation advice delivered at least annually, with behavioural support and pharmacotherapy offered to all smokers who are motivated to quit. Both guidelines point out that both NRT and bupropion are among the most cost effective of all healthcare interventions. NICE suggest the use of bupropion when NRT has failed and vice versa. Approximately $80 \%$ of smokers consult their general practitioner at least once each year, ${ }^{9}$ so this guidance, if implemented, could have a major impact on smoking rates.

Although information on the delivery of these interventions by general practitioners is scarce, the available data indicate that giving smoking cessation advice is far from routine, ${ }^{10}$ usually consists of brief advice only, ${ }^{11}$ and tends to be restricted to patients with a smoking related disease. ${ }^{12} \mathrm{~A}$ survey conducted in 2000, before NRT and bupropion were available on NHS prescription, found the opinions of general practitioner (GPs) divided; $42 \%$ thought these drugs should be available but $36 \%$ expressed concern that this would add unacceptably to their workload. ${ }^{13}$ Another small study estimated that GPs recommend NRT to fewer than $20 \%$ of smokers who could benefit from it. ${ }^{11}$

The main source of prescribing data in the UK is the Prescription Pricing Authority (PPA) which provides information on number and cost of items prescribed but these are not linked to individual patients. In its latest report on NRT and bupropion in 2002, the PPA reported that prescribing of NRT had increased notably since April 2001. In the quarter to December 2001, there were 240000 items for NRT costing $£ 5.2$ million. Prescribing of bupropion had declined from a peak of 146000 items in the quarter to March 2001 to under 37000 items in quarter to December 2001, thought to be due to concerns about its adverse effects. ${ }^{14}$

In this study we investigate the extent to which general practitioners prescribed smoking treatments during a two year period to April 2003, and explore the characteristics of smokers who did and did not receive these prescriptions.

Abbreviations: $\mathrm{Cl}$, confidence interval; $\mathrm{COPD}$, chronic obstructive pulmonary disease; GP, general practitioner; NHS, National Health Service; NICE, National Institute for Clinical Excellence; NRT, nicotine replacement therapy; OR, odds ratio; PCT, primary care trust; PPA, Prescription Pricing Authority; TIA, transient ischaemic attack 


\section{METHOD}

\section{Design, subjects, settings}

This was a cohort study conducted within 40 general practices contributing to the QRESEARCH pilot database (http://www.qresearch.org). ${ }^{15}$ This is a consolidated database containing the fully anonymised health records of participating practices' patients, updated quarterly. The pilot database included 40 practices in the former Trent Region of the NHS (covering South Yorkshire and East Midlands). To be eligible practices have to use EMIS, the most popular clinical computing software in the UK, and have their data accredited for quality and completeness. QRESEARCH contains only coded data (for example, prescriptions, smoking status) and cannot be used to investigate free text entries (for example, advice to quit smoking).

Our source population was the cohort of patients aged 18 or over on 1 April 2001 who were registered for the whole of the subsequent two year study period (ending 31 March 2003). As we were interested in deprivation, practices were included if more than $85 \%$ of registered patients had been successfully allocated to the Townsend score $^{16}$ associated with the electoral ward of their residence.

Our study population was all patients whose last Read coded entry in the five years from April 1996 to March 2001 indicated they were a smoker. Patients who did not have a record of smoking status, or whose last entry on smoking status was made before April 1996, were excluded. Our outcome was one or more prescriptions for smoking cessation treatment (NRT or bupropion) between April 2001 and March 2003. Our main explanatory variables of interest were the patient's sex and age (10 year age bands) and the Townsend deprivation score associated with the electoral ward in which the patient lived. We coded the Townsend score into fifths of increasing deprivation. Other variables included the following co-morbidities known to be well recorded on the database: asthma, or chronic obstructive pulmonary disease (COPD), ischaemic heart disease, myocardial infarction, hypertension, stroke or transient ischaemic attack (TIA) and diabetes. We also collected data on potential contraindications for bupropion-that is, diagnosis of bipolar disorder, brain tumour seizures or epilepsy (Read codes available from the authors) - and whether advice on quitting was recorded. We also extracted data on number of consultations during the two year study period and any coded record of advice to stop smoking. We did not aim to examine intensity of smoking as few practices code this information.

We compared the characteristics of smokers who were prescribed smoking cessation treatments in the two year study period with smokers who were not prescribed treatment. We used $\chi^{2}$ tests with adjustment for clustering by practice to compare proportions. We estimated the relative odds of receiving smoking cessation treatments among smokers using multi-level logistic regression which allowed for clustering by general practice by defining this as a level in the multi-level models. Unadjusted odds ratios were calculated for each characteristic and adjusted odds ratios were obtained by including all the characteristics in a multivariable model. Odds ratios were also calculated comparing characteristics of patients treated with bupropion with patients treated with NRT. Data were analysed using Stata (version 8.0). We selected a p value of 0.01 (two tailed) as being significant.

\section{RESULTS}

\section{Participants}

One practice was excluded from the final analysis as it was an extreme outlier, with a $92 \%$ prescribing rate for bupropion in smokers aged 18-24 years, suggesting it was participating in a drug trial. Our total eligible source population comprised 156550 patients aged 18 or more who were registered with the 39 practices during the whole two year study period. Of

Table 1 Completeness of recording and current smoking status for 158873 patients aged 18 or more (\% are row \% unless specified)

\begin{tabular}{|c|c|c|c|c|c|}
\hline & $\begin{array}{l}\text { Total population } \\
\text { Count } \\
n=156550\end{array}$ & $\begin{array}{l}\text { Smoking status } \\
\text { recorded } \\
\text { Count } \\
n=115449\end{array}$ & $\begin{array}{l}\% \text { with smoking } \\
\text { status recorded } \\
\text { Row \% } \\
73.7 \%\end{array}$ & $\begin{array}{l}\text { Current } \\
\text { smoker } \\
\text { Count } \\
n=29492\end{array}$ & $\begin{array}{l}\% \text { current smokers of } \\
\text { those with smoking } \\
\text { status recorded } \\
\text { Row } \% \\
25.5 \%\end{array}$ \\
\hline \multicolumn{6}{|l|}{ Age bands } \\
\hline $18-24$ & 14146 & 7654 & $54.1 \%$ & 2492 & $32.6 \%$ \\
\hline $25-34$ & 25134 & 17784 & $70.8 \%$ & 5213 & $29.3 \%$ \\
\hline $35-44$ & 31704 & 23029 & $72.6 \%$ & 6206 & $26.9 \%$ \\
\hline $45-54$ & 29315 & 23016 & $78.5 \%$ & 5962 & $25.9 \%$ \\
\hline $55-64$ & 22533 & 18338 & $81.4 \%$ & 5604 & $30.6 \%$ \\
\hline $65-74$ & 18601 & 15138 & $81.4 \%$ & 2584 & $17.1 \%$ \\
\hline 75 plus & 15117 & 10490 & $69.4 \%$ & 1431 & $13.6 \%$ \\
\hline \multicolumn{6}{|l|}{ Sex } \\
\hline Female & 78768 & 62021 & $78.7 \%$ & 14156 & $22.8 \%$ \\
\hline Male & 77782 & 53428 & $68.7 \%$ & 15336 & $28.7 \%$ \\
\hline \multicolumn{6}{|c|}{ Townsend quintile } \\
\hline 1 (Most affluent) & 31266 & 24268 & $77.6 \%$ & 4212 & $17.4 \%$ \\
\hline 2 & 33038 & 24787 & $75.0 \%$ & 5222 & $21.1 \%$ \\
\hline 3 & 28569 & 22361 & $78.3 \%$ & 6814 & $30.5 \%$ \\
\hline 4 & 31514 & 21124 & $67.0 \%$ & 6150 & $29.1 \%$ \\
\hline 5 (Most deprived) & 25595 & 18008 & $70.4 \%$ & 6304 & $35.0 \%$ \\
\hline $\begin{array}{l}\text { Missing } \\
\text { Morbidity }\end{array}$ & 6568 & 4901 & $74.6 \%$ & 790 & $16.1 \%$ \\
\hline Asthma & 20829 & 18159 & $87.2 \%$ & 4563 & $25.1 \%$ \\
\hline Cardiovascular & 6824 & 6272 & $91.9 \%$ & 909 & $14.5 \%$ \\
\hline $\mathrm{MI}$ & 3128 & 2904 & $92.8 \%$ & 394 & $13.6 \%$ \\
\hline Hypertension & 19913 & 18272 & $91.8 \%$ & 3649 & $20.0 \%$ \\
\hline Stroke or TIA & 3274 & 2831 & $86.5 \%$ & 496 & $17.5 \%$ \\
\hline Diabetes & 4668 & 4414 & $94.6 \%$ & 1103 & $25.0 \%$ \\
\hline
\end{tabular}


Table 2 Characteristics of patients who have and have not received nicotine replacement therapy (NRT) or bupropion

\begin{tabular}{|c|c|c|c|c|c|c|c|}
\hline & \multirow{2}{*}{$\begin{array}{l}\text { All smokers } \\
\\
\text { Count } \\
n=29492\end{array}$} & \multicolumn{6}{|c|}{ Treated smokers } \\
\hline & & $\begin{array}{l}\text { Had NRT or } \\
\text { bupropion } \\
\text { Count } \\
n=1892\end{array}$ & $\begin{array}{l}\% \text { of smokers } \\
\text { treated } \\
\text { Row\% } \\
6.4 \%\end{array}$ & $\begin{array}{l}\text { Had NRT } \\
\text { Count } \\
n=1486\end{array}$ & $\begin{array}{l}\% \text { of smokers } \\
\text { treated with NRT } \\
\text { Row } \% \\
5.0 \%\end{array}$ & $\begin{array}{l}\text { Had bupropion } \\
\text { Count } \\
n=514\end{array}$ & $\begin{array}{l}\% \text { of smokers } \\
\text { treated with } \\
\text { bupropion } \\
\text { Row \% } \\
1.7 \%\end{array}$ \\
\hline \multicolumn{8}{|l|}{ Age bands } \\
\hline $18-24$ & 2492 & 64 & $2.6 \%$ & 57 & $2.3 \%$ & 8 & $0.3 \%$ \\
\hline $25-34$ & 5213 & 331 & $6.3 \%$ & 257 & $4.9 \%$ & 92 & $1.8 \%$ \\
\hline $35-44$ & 6206 & 478 & $7.7 \%$ & 351 & $5.7 \%$ & 153 & $2.5 \%$ \\
\hline $45-54$ & 5962 & 437 & $7.3 \%$ & 336 & $5.6 \%$ & 130 & $2.2 \%$ \\
\hline $55-64$ & 5604 & 394 & $7.0 \%$ & 321 & $5.7 \%$ & 98 & $1.7 \%$ \\
\hline $65-74$ & 2584 & 155 & $6.0 \%$ & 136 & $5.3 \%$ & 28 & $1.1 \%$ \\
\hline 75 plus & 1431 & 33 & $2.3 \%$ & 28 & $2.0 \%$ & 5 & $0.3 \%$ \\
\hline \multicolumn{8}{|l|}{ Sex } \\
\hline Female & 14156 & 1099 & $7.8 \%$ & 902 & $6.4 \%$ & 266 & $1.9 \%$ \\
\hline Male & 15336 & 793 & $5.2 \%$ & 584 & $3.8 \%$ & 248 & $1.6 \%$ \\
\hline \multicolumn{8}{|l|}{ Townsend quintile } \\
\hline 1 (Most affluent) & 4212 & 239 & $5.7 \%$ & 169 & $4.0 \%$ & 80 & $1.9 \%$ \\
\hline 2 & 5222 & 296 & $5.7 \%$ & 244 & $4.7 \%$ & 65 & $1.2 \%$ \\
\hline 3 & 6814 & 344 & $5.0 \%$ & 267 & $3.9 \%$ & 95 & $1.4 \%$ \\
\hline 4 & 6150 & 425 & $6.9 \%$ & 321 & $5.2 \%$ & 132 & $2.1 \%$ \\
\hline 5 (Most deprived) & 6304 & 545 & $8.6 \%$ & 460 & $7.3 \%$ & 122 & $1.9 \%$ \\
\hline Missing & 790 & 43 & $5.4 \%$ & 25 & $3.2 \%$ & 20 & $2.5 \%$ \\
\hline \multicolumn{8}{|l|}{ Morbidity } \\
\hline Asthma & 4563 & 468 & $10.3 \%$ & 387 & $8.5 \%$ & 105 & $2.3 \%$ \\
\hline Cardiovascular & 909 & 113 & $12.4 \%$ & 96 & $10.6 \%$ & 27 & $3.0 \%$ \\
\hline $\mathrm{MI}$ & 394 & 46 & $11.7 \%$ & 40 & $10.2 \%$ & 10 & $2.5 \%$ \\
\hline Hypertension & 3649 & 244 & $6.7 \%$ & 200 & $5.5 \%$ & 58 & $1.6 \%$ \\
\hline Stroke or TIA & 496 & 56 & $11.3 \%$ & 49 & $9.9 \%$ & 7 & $1.4 \%$ \\
\hline Diabetes & 1103 & 78 & $7.1 \%$ & 69 & $6.3 \%$ & 12 & $1.1 \%$ \\
\hline $\begin{array}{l}\text { One or more contra- } \\
\text { indications for bupropion }\end{array}$ & 698 & 65 & $9.3 \%$ & 61 & $8.7 \%$ & 4 & $0.6 \%$ \\
\hline \multicolumn{8}{|l|}{ Consultations } \\
\hline No consultations & 4357 & 71 & $1.6 \%$ & 51 & $1.2 \%$ & 23 & $0.5 \%$ \\
\hline $1-4$ consultations & 8157 & 228 & $2.8 \%$ & 161 & $2.0 \%$ & 76 & $0.9 \%$ \\
\hline 5-10 consultations & 8400 & 545 & $6.5 \%$ & 413 & $4.9 \%$ & 164 & $2.0 \%$ \\
\hline 11 plus consultations & 8578 & 1048 & $12.2 \%$ & 861 & $10.0 \%$ & 251 & $2.9 \%$ \\
\hline
\end{tabular}

these, $115449(73.7 \%)$ had smoking status recorded in the five years before the start of the study period and, of these, $29492(25.5 \%)$ were coded as current smokers. Recording was higher in females, older age groups, and if co-morbidity was present (all p $<0.001$ ) (table 1$)$. Current smokers were more likely to be younger $(p<0.001)$, male $(p=0.015)$, and to come from the most deprived areas $(p<0.001)$ (table 1). Those with co-morbidities were less likely to be current smokers (cardiovascular disease, myocardial infarction, stroke all $\mathrm{p}<0.01$, hypertension $\mathrm{p}=0.055$ ).

\section{Characteristics of treated and untreated smokers}

Overall, 1892 (6.4\%) of the 29492 people recorded as current smokers at the start of the study period were given prescriptions for smoking cessation treatment during the subsequent two years (table 2$)$. Of these, 1378 (72.8\%) were given NRT alone, 406 (21.5\%) bupropion alone, and 108 (5.7\%) both treatments. Among the 27600 smokers who were not treated, $23314(84.5 \%)$ had consulted their GP at least once during the study period, and 7530 (27.3\%) consulted more than 10 times. Smoking cessation advice was coded in $23.3 \%(440 / 1892)$ of those given treatment and $3.5 \%(971 / 27600)$ of smokers who were not treated.

The characteristics of the 1892 patients who received at least one prescription for smoking cessation treatment were compared with the 27600 who did not (table 3). Smokers were more likely to receive smoking cessation treatment if they lived in the most deprived areas (odds ratio (OR) for the most relative to the least deprived fifth, adjusted for sex, age, and co-morbidity, $1.50,95 \%$ confidence interval (CI) 1.26 to 1.78 ), and less likely to if they were male (adjusted OR 0.68 , $95 \%$ CI 0.62 to 0.75 ). Patients aged between $25-74$ were more likely to be receive treatment than younger (18-24) and older (75 plus) patients.

Smokers with co-morbidity were more likely to receive smoking cessation treatment, and this was significant $(\mathrm{p}<0.01)$ for those with asthma, ischaemic heart disease, hypertension, and stroke (table 3). Prescription of smoking cessation treatment varied significantly between general practices, the overall median proportion treated being $6.4 \%$ with an interquartile range of $4.5 \%$ to $9.3 \%$ (range $0.0-$ $18.6 \%)$, and intracluster correlation coefficient of 0.02 .

\section{Use of smoking cessation treatments and contraindications}

Of the 698 patients who received bupropion, there were four patients $(0.6 \%)$ who had one or more contraindications for bupropion; these patients all had pre-existing epilepsy and one also had an eating disorder.

\section{Choice of smoking treatment}

The characteristics of smokers who received bupropion are compared with those who received NRT, excluding the 108 patients who received both treatments, in table 4 . The table shows that relative to NRT, bupropion was used in a higher proportion of older smokers and in males. There was no clear trend with deprivation. It was used somewhat less in patients with diabetes $(p<0.05)$. 


\begin{tabular}{|c|c|c|c|c|c|c|}
\hline & $\begin{array}{l}\text { Unadjusted } \\
\text { OR }\end{array}$ & $95 \% \mathrm{Cl}$ & $\mathrm{p}$ Value & $\begin{array}{l}\text { Adjusted } \\
\text { OR }\end{array}$ & $95 \% \mathrm{Cl}$ & $p$ Value \\
\hline $\begin{array}{l}\text { Age band } \\
18-24\end{array}$ & \multicolumn{5}{|c|}{ Age band } & \\
\hline $25-34$ & 2.51 & $(1.90$ to 3.31$)$ & $<0.001$ & 2.91 & (2.18 to 3.88 ) & $<0.001$ \\
\hline $35-44$ & 3.18 & (2.43 to 4.16 ) & $<0.001$ & 3.78 & (2.85 to 5.00$)$ & $<0.001$ \\
\hline $45-54$ & 3.12 & (2.38 to 4.10 ) & $<0.001$ & 3.57 & (2.69 to 4.73 ) & $<0.001$ \\
\hline $55-64$ & 3.07 & (2.34 to 4.04 ) & $<0.001$ & 3.27 & (2.45 to 4.36 ) & $<0.001$ \\
\hline 65-74 & 2.47 & (1.83 to 3.34 ) & $<0.001$ & 2.03 & (1. .48 to 2.80 ) & $<0.001$ \\
\hline 75 plus & 1.14 & (0.74 to 1.76 ) & 0.555 & 0.95 & (0.60 to 1.49 ) & 0.826 \\
\hline \multicolumn{7}{|c|}{ (0.00 } \\
\hline Female & 1.00 & & & 1.00 & & \\
\hline Male & 0.69 & (0.63 to 0.76$)$ & $<0.001$ & 0.68 & $(0.62$ to 0.75$)$ & $<0.001$ \\
\hline \multicolumn{7}{|l|}{ Townsend quintile } \\
\hline 1 (Most affluent) & 1.00 & & & 1.00 & & \\
\hline 2 & 1.10 & (0.90 to 1.34 ) & 0.337 & 1.07 & (0.89 to 1.29 ) & 0.485 \\
\hline 3 & 0.97 & (0.81 to 1.16 ) & 0.738 & 0.93 & $(0.77$ to 1.11$)$ & 0.410 \\
\hline 4 & 1.14 & $(0.96$ to 1.36$)$ & 0.138 & 1.10 & (0.93 to 1.31 ) & 0.280 \\
\hline $\begin{array}{l}5 \text { (Most deprived) } \\
\text { Morbidity* }\end{array}$ & \multicolumn{6}{|c|}{ Morbidity* } \\
\hline Asthma/COPD & 1.77 & (1.55 to 2.04 ) & $<0.001$ & 1.80 & (1.60 to 2.02$)$ & $<0.001$ \\
\hline IHD & 2.01 & (1.63 to 2.47 ) & $<0.001$ & 2.09 & (1.66 to 2.62 ) & $<0.001$ \\
\hline Hypertension & 1.31 & (1.13 to 1.51 ) & $<0.001$ & 1.25 & (1.06 to 1.47 ) & 0.007 \\
\hline Stroke & 1.70 & (1.28 to 2.27 ) & $<0.001$ & 1.60 & (1.16 to 2.19 ) & 0.004 \\
\hline Diabetes & 1.33 & (1.04 to 1.70 ) & 0.021 & 1.21 & (0.94 to 1.56 ) & 0.147 \\
\hline
\end{tabular}

\section{Time trends}

Numbers were considered too small for a time analysis but this has been done on the substantive QR data set for the period April 2001 to March 2004 and shows a steady increase in the number of patients prescribed NRT, whereas prescribing of bupropion has been stable at a low level. Results can be viewed at http://www.qresearch.org

\section{DISCUSSION}

This is the first study to report on the prescribing of smoking cessation treatments in UK general practice and factors that predict its use. Over our two year study period only $6.4 \%$ of patients recorded as smokers received one or more of these products. There is evidence from several sources to suggest that a higher proportion of consulting smokers could benefit from these treatments. A recent population survey found that $10 \%$ of current smokers reported an intention to quit in the next month. ${ }^{17}$ More directly relevant, a survey of smokers conducted after a consultation with their GP found that $25 \%$ intended to quit within one month, ${ }^{11}$ rising to $37 \%$ of those who considered they had a smoking related problem. ${ }^{18}$ In the present study over $80 \%$ of untreated smokers had consulted their GP during the two year study period, with over a quarter consulting more than 10 times, indicating that there are missed opportunities for prescribing smoking cessation treatments.

\begin{tabular}{|c|c|c|c|c|c|c|}
\hline & $\begin{array}{l}\text { Unadjusted } \\
\text { OR }\end{array}$ & $95 \% \mathrm{Cl}$ & $p$ value & $\begin{array}{l}\text { Adjusted } \\
\text { OR }\end{array}$ & $95 \% \mathrm{Cl}$ & p value \\
\hline \multicolumn{7}{|l|}{ Age band } \\
\hline $18-24$ & 1.00 & & & 1.00 & & \\
\hline $25-34$ & 2.31 & (0.98 to 5.45 ) & 0.056 & 2.21 & (0.92 to 5.31$)$ & 0.075 \\
\hline $35-44$ & 3.04 & (1.31 to 7.06 ) & 0.010 & 2.92 & (1.24 to 6.86 ) & 0.014 \\
\hline $45-54$ & 2.32 & (0.99 to 5.40 ) & 0.052 & 2.25 & (0.95 to 5.34 ) & 0.066 \\
\hline $55-64$ & 1.76 & (0.75 to 4.13 ) & 0.197 & 1.69 & (0.70 to 4.06 ) & 0.241 \\
\hline $65-74$ & 1.04 & (0.40 to 2.70 ) & 0.935 & 1.10 & (0.40 to 2.97 ) & 0.857 \\
\hline 75 plus & 1.06 & $(0.29$ to 3.87$)$ & 0.926 & 1.11 & $(0.29$ to 4.26$)$ & 0.884 \\
\hline \multicolumn{7}{|l|}{ Sex } \\
\hline Female & 1.00 & & & 1.00 & & \\
\hline Male & 1.67 & (1.32 to 2.11$)$ & $<0.001$ & 1.70 & (1.33 to 2.18 ) & $<0.001$ \\
\hline \multicolumn{7}{|l|}{ Townsend quintile } \\
\hline 1 (Most affluent) & 1.00 & & & 1.00 & & \\
\hline 2 & 0.61 & (0.37 to 1.00$)$ & 0.049 & 0.61 & $(0.37$ to 1.00$)$ & 0.052 \\
\hline 3 & 0.76 & $(0.48$ to 1.20 ) & 0.241 & 0.78 & (0.49 to 1.24 ) & 0.300 \\
\hline 4 & 0.97 & (0.62 to 1.51 ) & 0.883 & 1.03 & $(0.66$ to 1.61$)$ & 0.897 \\
\hline $\begin{array}{l}5 \text { (Most deprived) } \\
\text { Morbidity* }\end{array}$ & 0.54 & (0.33 to 0.88 ) & 0.013 & 0.61 & (0.37 to 0.99 ) & 0.047 \\
\hline Asthma/COPD & 0.77 & $(0.58$ to 1.03$)$ & 0.082 & 0.91 & $(0.67$ to 1.23$)$ & 0.528 \\
\hline IHD & 0.60 & (0.35 to 1.06 ) & 0.077 & 0.78 & $(0.42$ to 1.46$)$ & 0.441 \\
\hline Hypertension & 0.74 & (0.51 to 1.07 ) & 0.111 & 1.09 & (0.72 to 1.64 ) & 0.696 \\
\hline Stroke & 0.46 & $(0.20$ to 1.06$)$ & 0.068 & 0.51 & (0.19 to 1.37 ) & 0.181 \\
\hline Diabetes & 0.42 & $(0.20$ to 0.89$)$ & 0.022 & 0.46 & $(0.21$ to 0.99$)$ & 0.048 \\
\hline
\end{tabular}




\section{What this paper adds}

Smoking cessation treatments are the most cost effective treatment available in the National Health Service. Recent guidelines have emphasised the importance of general practice in providing treatment to smokers motivated to quit. Prescribing rates of smoking cessation treatments are low with less than $7 \%$ of smokers receiving treatment. Given that this is the most cost effective treatment available, treatment rates need to be substantially increased. Women, those with co-morbidities, and those from deprived areas are more likely to be prescribed smoking cessation treatments.

About three times as many smokers received a prescription for NRT than bupropion, suggesting the former is first line treatment for motivated smokers. Reasons for this could be the stronger evidence base for effectiveness, concern about side effects with bupropion, or patient preference. As expected we found higher rates of prescribing in patients with co-morbidities, suggesting again that GPs target patients with smoking related diseases. GPs were also more likely to prescribe to smokers in deprived groups; this may be because more affluent smokers buy supplies of NRT over the counter with or without a consultation with their GP. A major source of variation between practices is likely to be differences in local policy on prescribing by smoking cessation services; in some areas the service provides supplies while in others clients are asked to obtain a prescription from their GP.

The finding that less than $5 \%$ of smokers had a record of advice about smoking is lower than other studies ${ }^{19}$ and is almost certainly due to these data being entered into electronic medical records as free text rather than an extractable Read code. This situation is likely to change rapidly in response to the new GP contact which includes quality payments for this activity. ${ }^{20}$

\section{Study limitations}

The main limitation of this study is that we relied on routinely collected GP data. Although this is accurate for prescribing, and smoking ascertainment rates are high, other relevant information, such as whether the prescription was triggered by a smoking cessation service, are not recorded by GPs in extractable form, nor was it possible to obtain accurate information about duration of treatment and follow up. As we used data on smoking status that were up to five years old to define our cohort we will have included a small number of people who, unbeknown to their GP, stopped smoking during this period, thereby underestimating the percentage of current smokers receiving treatment. We are addressing some of these questions in a parallel study by sending a questionnaire to those who have recently been issued a prescription for NRT or bupropion.

Despite these limitations, a clear message emerges that a major health promotion opportunity is being missed by low implementation of cessation guidelines in primary care.

\section{ACKNOWLEDGEMENTS}

We thank David Stables (EMIS) for helping set up QRESEARCH and the practices for contributing data. Thanks also to Ronan Ryan for his contribution to data analysis and members of the project steering group for their advice and support.

\section{CONTRIBUTORS}

AW is guarantor of the paper. AW, TC, CC developed the original protocol and obtained funding. JHC obtained MREC approval, contributed to the initiation and design, data extraction, coding, validation, checked the analysis, wrote the first draft of the paper and is guarantor of the data. CC and SB carried out the analysis. All authors contributed to protocol development and interpretation of results.

\section{Authors' affiliations}

A Wilson, Department of Health Sciences, University of Leicester, Leicester, UK

J Hippisley-Cox, C Coupland, T Coleman, S Barrett, Division of Primary Care, University of Nottingham, Nottingham, UK

J Britton, Division of Respiratory Medicine, University of Nottingham

Funding: Access to data was funded by a grant from the Health Development Agency. The analyses and report were done without any additional funding.

Competing interests: $\mathrm{AW}$, none; JHC, none; $\mathrm{CC}$, none; TC has been paid (once) for speaking by Glaxo-Smith Kline and for consultancy work by Pharmacia 2002. JB has received an honorarium from Glaxo-SmithKline and had research funded by Pharmacia; SB, none

Ethical approval: Trent Multi-Centre Research Ethics Committee

\section{REFERENCES}

1 Doll R, Peto R, Boreham J, et al. Mortality in relation to smoking: 50 years' observations on male British doctors. BMJ 2004;328:1519-28.

2 Britton J, Jarvis MJ. Bupropion: a new treatment for smokers. Nicotine replacement treatment should also be available on the NHS. BMJ 2000;321:65-6.

3 Coleman T, West R. Newly available treatments for nicotine addiction. Smokers wanting help with stopping now have effective treatment options. BMJ 2001;322:1076-7.

4 National Health Service. The NHS Plan. A plan for investment, a plan for reform. London: HMSO, 2000.

5 West R, McNeill A. Meeting Department of Health smoking cessation targets. Recommendations for primary care trusts. London: Health Development Agency, 2003.

6 West R, McNeill A, Raw M. Meeting Department of Health smoking cessation targets. Recommendations for service providers. London: Health Development Agency, 2003.

7 West R, McNeill A, Raw M. Smoking cessation guidelines for health professionals: an update. Thorax 2000;55:987-99.

8 National Institute for Clinical Excellence. Guidance on the use of nicotine replacement therapy (NRT) and bupropion for smoking cessation. NHS. Technology Appraisal No 39. London: NICE, 2002.

9 McCormick A, Fleming DM, Charlton J. Morbidity statistics from general practice: fourth national study, 1991-1992. London: HMSO, 1995.

10 Coleman T, Wynn AT, Barrett S, et al. Intervention study to evaluate pilot health promotion payment aimed at increasing general practitioners' antismoking advice to smokers. BMJ 2001;323:435-6.

11 Coleman T, Wynn A, Barrett S, et al. Discussion of NRT and other antismoking interventions in UK general practitioners' routine consultations. Nicotine Tob Res 2003;5:163-8.

12 Thorndike AN, Rigotti NA, Stafford RS, et al. National patterns in the treatment of smokers by physicians. JAMA 1998;279:604-8.

13 McEwen A, West R, Owen L. General Practitioners' views on the provision of nicotine replacement therapy and bupropion. BMC Family Practice 2001;2.

14 Prescription Pricing Authority. Cardiovascular Prescribing. 2002. PPA http:// www.ppa.org.uk/news/pact-012002.htm.

15 Hippisley-Cox J, Stables D, Pringle M. QRESEARCH: a new general practice database for research. Informatics in Primary Care 2004;12:49-50.

16 Townsend P. Deprivation. Journal of Social Policy 1987;16:125-46.

17 Meltzer H. Smoking related behaviour and attitudes, 2002. London: Office for National Statistics, 2003.

18 Coleman T, Barrett S, Wynn A, et al. Comparison of the smoking behaviour and attitudes of smokers who believe they have smoking-related problems with those who do not. Family Practice 2003;20:520-3.

19 Wilson A, McDonald P. Comparison of patient questionnaire, medical record, and audio tape in assessment of health promotion in general practice consultations. BMJ 1994;309:1483-5.

20 The NHS Confederation. New GMS Contract 2003: investing in general practice. General Practitioners Committee. London: British Medical Association, 2003. 